\title{
CONTROLAR PARA CONFIAR? UMA ANÁLISE DO RISCO PERCEBIDO EM RELACIONAMENTOS DE UMA CADEIA DE SUPRIMENTOS
}

\section{CONTROLLING FOR TRUST? AN ANALYSIS OF PERCEIVED RISK RELATIONSHIPS IN A SUPPLY CHAIN}

\begin{abstract}
Wagner Junior Ladeira
Mestre em Administração pela Universidade Federal do Rio Grande do Sul. Doutorando da Universidade Federal do Rio Grande do Sul. Professor da Universidade Vale do Rio do Sinos. wjladeira@ea.ufrgs.br

Diego Antonio Bittencourt Marconatto Mestre em Administração pela Universidade Federal de Santa Maria. Doutorando da Universidade Federal do Rio Grande do Sul. dmarconatto@gmail.com

Vania de Barros Estivalete vaniaestivalete@ufsm.br
\end{abstract}

Submissão: 08/03/2011 Aprovação: 15/07/2012

\section{Resumo}

A crescente competição exige novas formas de interação organizacional que deem maior ênfase à confiança, em detrimento aos controles de natureza mais formal. Surge uma nova concepção, que enseja o paradoxo dos relacionamentos, com foco na "co-opetição". Como os relacionamentos interorganizacionais envolvem relações de risco, a confiança e o controle atuam como personagens-chave nesse contexto, com o objetivo primordial de reduzi-los. Assim, este estudo objetivou explorar como a confiança e os controles afetam o risco percebido em relações interorganizacionais, ao longo do tempo, no âmbito de uma cadeia de suprimentos, com a utilização do framework de Das e Teng (2001). Duas empresas participaram da pesquisa: uma fabricante de bebidas não alcoólicas e uma prestadora de serviços de gestão ambiental. O método de pesquisa adotado foi o do estudo de casos múltiplos, e as ferramentas usadas para a coleta de dados foram entrevistas semiestruturadas e análise documental. Os resultados revelaram ligações diretas entre os diversos tipos de controle, os tipos de confiança e tipos de risco percebido, assim como alterações na natureza dessas ligações durante a evolução do relacionamento entre ambas as empresas.

Palavras-chave: Controle. Confiança. Risco. Relacionamento estratégico. Cadeia de suprimentos. 


\begin{abstract}
The increasing competition demands new forms of organizational interaction, giving greater emphasis to trust, to the detriment of a more formal controls. A new design, which entails the paradox of relationships, focusing on co-opetition. As the inter-relationships involve risk relations, trust and control act as key characters in this context, the primary goal of reducing them. This study aimed to explore how trust and controls affect the perceived risk in interfirm relations over time within a supply chain, using the framework of Das and Teng (2001). Two companies participated in the survey: a manufacturer of soft drinks and a provider of environmental management services. The research method used was the multiple case study and the tools used to collect data were semi-structured interviews and documentary analysis. The results revealed direct links between the various types of control, reliable brands and types of perceived risk, as well as changes in the nature of these connections during the evolving relationship between both companies.
\end{abstract}

Key-words: Control. Trust. Risk. Strategic relationship. Supply chain. 


\section{INTRODUÇÃO}

O crescente acirramento competitivo entre organizações acaba por gerar um novo paradigma: o dos relacionamentos entre clientes e fornecedores (SAHAY, 2003; WU et al., 2004), que se refere a todas as atividades ligadas ao estabelecimento, desenvolvimento e manutenção de trocas relacionais de sucesso. Esse paradigma encerra, ao mesmo tempo, um paradoxo: para um player ser um efetivo competidor (na economia global), ele precisa ser também um cooperador confiável (MORGAN; HUNT, 1994). Isto implica a coexistência da competição e da cooperação em um mesmo relacionamento, sendo cunhado, inclusive, um termo para esse fenômeno: a "co-opetição" (BRANDENBURGER; NALEBUFF, 1997).

Um dos modos por meio do qual tais relacionamentos ganham realidade é materializado nas redes interorganizacionais. Dentre as várias tipologias de redes, a chamada cadeia de suprimentos ou supply chain (de orientação verticalizada), vem ganhando cada vez mais atenção (LARSON; ROGERS, 1998). De acordo com a linha de pensamento de Chu e Fang (2006), o princípio básico que sustenta o conceito de gerenciamento de cadeia de suprimentos é o planejamento efetivo interorganizacional da cadeia, baseado no compartilhamento de informação e na confiança. De fato, relacionamentos interorganizacionais requerem confiança para a colaboração de longo prazo, incluindo uma predisposição a assumir riscos. Como sustentam Morgan e Hunt (1994), a confiança é um prérequisito essencial para o comprometimento entre parceiros de uma cadeia de suprimentos.

Há, no entanto, uma contrapartida que deve ser mencionada. Conforme Bachmann (1999) postula, a confiança reduz incertezas, mas produz riscos, visto que um indivíduo que decide confiar em outro extrapola o limite de suas informações disponíveis sobre o comportamento futuro deste último. Há então a necessidade inerente de lidar com esse risco, sendo que esta constatação leva a outro arcabouço teórico importante: o controle

Diante dessa perspectiva, confiança e controle, de acordo com uma série de autores (BIJLSMA-FRANKEMA; COSTA， 2005; DAS; TENG， 2001; DAS; TENG， 1998; BACHMANN, 1999; MÖLLERING, 2005), estão intimamente imbricados e ambos têm, em conjunto, a função primeira de aumentar a previsibilidade das ações dos atores sociais e, logo, de diminuir os riscos de geração de perdas nas transações mantidas entre eles. Entretanto analisar a confiança e o controle de modo isolado tende a limitar o entendimento mais aprofundado desses constructos (MÖLLERING, 2005). Vários autores, como, por, exemplo, Larson e Rogers (1998) e Das e Teng (2001), propõem uma visão conjunta dessas temáticas, 

existindo ainda o risco como um fator inerente a ambos. Esses dois últimos estudiosos chegam a mencionar que "confiança e controle são constructos inseparáveis quando se trata de incerteza e de risco" e que "não há um terceiro determinante de importância comparável à confiança e ao controle - no que tange, novamente, ao risco e à incerteza relacionais" (DAS; TENG; 2001, p. 253).

Inkpen e Currall (2004), por sua vez, imbricam tais teorias sob uma perspectiva coevolucionária, com o objetivo de melhor compreender como a confiança, os controles interorganizacionais - e, adicionalmente, a aprendizagem influenciam-se mutuamente, no ambiente das joint ventures (JV). Segundo esses mesmos autores, as literaturas que tratam de confiança, controle e aprendizagem em JV não têm sido articuladas de forma sistemática, deixando lacunas no entendimento teórico do relacionamento entre os conceitos (INKPEN; CURRALL, 2004). O presente artigo tem a intenção de evoluir nessa linha de investigação entretanto, excluindo a aprendizagem - e com o foco em relacionamentos interorganizacionais existentes em cadeias de suprimentos (que têm uma configuração diversa das JV), por meio das seguintes questões de pesquisas: Como a confiança e os controles afetam-se mutuamente? E como ambos afetam o nível de risco relacional e de performance percebido em relacionamentos interorganizacionais em cadeias de suprimentos?

Essas questões de pesquisa levam aos seguintes objetivos: a) investigar a confiança, os controles e os riscos interorganizacionais sob uma perspectiva evolutiva em uma díade de uma cadeia de suprimentos; e b) contribuir teórica e empiricamente no desenvolvimento dos conhecimentos a respeito do relacionamento entre essas variáveis. A consecução desses objetivos secundários dá a base para o atingimento do objetivo principal deste trabalho, que é explorar o impacto que os tipos de confiança e controle exercem sobre o risco percebido em relacionamentos interorganizacionais em uma díade no âmbito de uma cadeia de suprimentos, com o auxílio do modelo teórico desenvolvido por Das e Teng (2001). 


\section{REFERENCIAL TEÓRICO}

Para o atingimento do objetivo, o artigo estrutura sua base teórica da seguinte forma: primeiro, serão tratados o conceito de cadeia de suprimentos, sua conceituação e sua evolução; depois, será abordado o constructo da confiança interorganizacional; em seguida, são expostos os controles e sua relação com a confiança e os riscos percebidos. Explicados esses tópicos, todos os conceitos são desenvolvidos em um framework único para, posteriormente, serem apresentados os resultados com sua subsequente discussão.

\subsection{A Cadeia de Suprimentos (Supply Chain): conceituação e evolução}

Mudanças rápidas no ambiente competitivo estão forçando as empresas a procurarem meios mais criativos e flexíveis de enfrentar a competição. Muitas empresas têm respondido a esse desafio na construção de relacionamentos colaborativos com clientes e fornecedores (DONEY; CANNON, 1997). As cadeias de suprimentos - um conceito que surgiu na década de 1950, com base na teoria dos sistemas e associada à noção de holismo (NEW, 1997) materializam uma dessas formas de construção. O conselho Americano de Supply Chain define o gerenciamento da cadeia de suprimentos como "um conjunto de esforços envolvidos em produzir e entregar um produto final, a partir do fornecedor do fornecedor até o cliente do cliente" (SCC, 2008). Esses esforços são divididos em cinco atividades principais: planejar, suprir, fazer, entregar e retornar. Independentemente do autor, os conceitos de cadeia de suprimentos normalmente trazem consigo a noção de interligação entre firmas, que, em certo momento, cumprem o papel de clientes e, em outro, o de fornecedor, até chegar-se ao final da cadeia, que é a empresa ou consumidor final.

Entretanto o conceito de gerenciamento de cadeia de suprimentos vem evoluindo ao longo dos anos. A visão tradicional de gerenciamento de cadeia de suprimentos visava levar a cadeia a atingir o menor valor inicial de compra possível, concomitantemente assegurando o fornecimento. De modo diverso, a essência do novo gerenciamento da cadeia de suprimentos é torná-la um recurso estratégico para desenvolver uma vantagem competitiva sustentável por meio da redução de investimentos sem sacrificar a satisfação do consumidor (LEE; BILLINGTON, 1992). Adicionalmente, os parceiros das novas cadeias de suprimentos compartilham abertamente informações que facilitam suas habilidades em preencher as necessidades dos clientes finais. Enquanto a redução de custos é tipicamente um resultado, o gerenciamento da cadeia de suprimentos deve enfatizar o aumento das habilidades, expertises 
e capacidades das firmas que compreendem sua rede (SPEKMAN; KAMAUFF; MYHR, 1998).

Dessa forma, Huan, Sunil e Wang (2004) sugerem que as linhas de pesquisa em supply chain devem esforçar-se mais em desenvolver um framework para a geração e a manutenção de relacionamentos interorganizacionais. Nota-se, assim, que, nos últimos anos, uma série de autores começou a mesclar diferentes concepções teóricas na busca de melhores resultados no que tange à investigação das cadeias de suprimentos, enfocando o impacto causado por variáveis não econômicas, como a confiança (WU et al., 2004; KWON; SUH, 2004; BARNEY; HANSEN, 1994; SVENSSON, 2001; MORGAN; HUNT; 1994). Essa afirmação assemelha-se ao ideário de Granovetter (1985), quando ele afirma que existe um componente social significativo nos relacionamentos de trocas que normalmente é omitido nas explicações puramente econômicas de tais trocas.

Com base no exposto, a confiança é um constructo muito importante em cadeias de suprimentos. Para alguns autores, como, por exemplo, Morgan e Hunt (1994), a confiança ganha o status quo de elemento fundamental dos relacionamentos interorganizacionais em cadeias de suprimentos. Assim sendo, faz-se necessária uma análise mais aprofundada desse constructo.

\subsection{A confiança no âmbito dos relacionamentos interorganizacionais}

Por muitos anos, o construto da confiança tem captado interesse de várias áreas de estudo (SVENSSON, 2001). Morgan e Hunt (1994), por exemplo, chamaram a confiança de principal determinante no comprometimento de um relacionamento. Tais autores consideram a confiança um elemento-chave pelo fato de encorajar os negociadores a diminuírem a incerteza na tomada de decisão e a resistirem às alternativas atrativas de curto-prazo (oportunismo), em prol dos benefícios de longo prazo; e a visualizarem as ações de alto risco como sendo prudentes, devido à crença de que seus parceiros não agirão de modo oportunista (diminuição do risco percebido).

Barney e Hansen (1994) entendem a confiança como sendo a mútua confidência de que nenhuma das partes que mantêm relação entre si explorará as vulnerabilidades da outra parte. Morgan e Hunt (1994), por sua vez, dizem que a confiança existe quando uma parte tem fé na integridade e confiabilidade da outra parte. Nesses conceitos, verifica-se, explícita ou implicitamente, a noção de vulnerabilidade, risco e incerteza da relação, geradas pela racionalidade limitada (WILLIAMSON, 1985). Como uma parte não tem certeza de como a 
outra parte se comportará em relação a determinada situação, há a necessidade de confiar para o estabelecimento da relação, sendo que é nessa relação de confiança em si que reside a vulnerabilidade (risco).

Há ainda de considerar-se a existência de diferentes tipos de confiança. Entre os principais, destacam-se dois: a confiança pura e a confiança baseada em competência (DAS; TENG; 2001). A confiança pura diz respeito às boas intenções, à fé e à integridade; ou seja, a confiança pura distancia-se do conceito de confiança de Coleman (1990, apud DAS; TENG; 2001), de base puramente econômica e "calculativa". A confiança baseada em competências está estruturada sobre a percepção da capacidade da outra parte em cumprir com suas obrigações relacionais. Todos os dois tipos de confiança naturalmente acabam por afetar os relacionamentos interorganizacionais quanto a sua qualidade e intensidade e, por consequência, seus outputs. Como a confiança age sobre as vulnerabilidades relacionais, tendendo diminuí-las, alguns autores investigam a possibilidade da confiança funcionar como um mecanismo de governança (BIJLSMA-FRANKEMA; COSTA, 2005; MÖLLERING, 2005). Esses e outros autores tratam ainda da confiança em conjunto com o controle, de forma a ambos ou se complementarem-se ou se substituírem. Bachmann (1999), por exemplo, trabalha os constructos de maneira substitutiva, enquanto Möllering (2005) entende os dois como sendo inextrincáveis. Independente do enfoque, os autores tratam esses constructos juntamente com a percepção de risco, inerente, em menor ou maior grau, aos relacionamentos interorganizacionais. Mais importante, no entanto, é entender que a confiança, o controle e o risco trazem efeitos diversos um sobre o outro (INKPEN; CURRALL, 2004) e, assim sendo, deve-se também compreender a dinâmica dos controles e dos riscos interorganizacionais.

\subsection{Os controles e os riscos em relacionamentos interorganizacionais}

Das e Teng (1998, p. 493) conceituam mecanismos de controle como "arranjos organizacionais projetados para determinar e influenciar o que os membros organizacionais farão, enquanto nível de controle é o grau em que determinado comportamento é garantido”. Em suma, controles são utilizados para tornarem o atingimento das metas organizacionais mais previsíveis e assim diminuir os riscos inerentes às diversas operações empresariais.

Os riscos são muito importantes no entendimento da relação controle-confiança, pois tanto o controle quanto a confiança têm entre suas principais metas a redução, cada um a seu modo, da percepção da possibilidade de ocorrência de resultados negativos, que nada mais é do que risco (DAS; TENG, 2001). O risco também é vital na relação confiança-controle, 

porque as empresas que estabelecem transações têm, cada qual, uma percepção do nível máximo de risco a que podem submeter-se, além do que a aliança se torna demasiadamente perigosa para elas (BACHMANN, 1999). Assim, é natural supor que diferentes percepções de risco demandam diferentes níveis e tipos de controles e confiança; assim como quanto maior a sensibilidade ao risco, maiores precisam ser a confiança e os controles, sendo o inverso igualmente lógico.

Das e Teng (2001) mostram duas tipologias básicas de risco no que tange a relacionamentos interorganizacionais. Primeiro, há o risco relacional, que é aquele baseado na probabilidade de incursão de uma das partes em comportamentos oportunistas, que podem gerar perdas assimétricas entre os parceiros. Em segundo, há o risco de performance, que concerne à possibilidade de ineficácia da parceria por questões estruturais externas ou por incompetência das partes em cumprir com suas respectivas obrigações relacionais (DAS; TENG, 2001).

Tanto o risco relacional quanto o de performance têm duas dimensões: a real e a percebida (DAS; TENG, 2001). A dimensão real mostra o tamanho, e o tipo factível do risco é de difícil mensuração, enquanto a dimensão percebida está condicionada à percepção de cada parte. Isto torna a definição mútua e a institucionalização dos controles interorganizacionais mais difíceis e menos simples do que se pode normalmente cogitar, pois os parceiros, não raras vezes, discordam do que controlar e como controlar devido, exatamente, a suas percepções dissonantes (INKPEN; CURRALL, 2004).

Mesmo perante tais dificuldades, controles são comuns e são institucionalizados por meio de estruturas de governança, especificações contratuais, arranjos gerenciais e outros mecanismos mais informais (DAS; TENG, 2001). Segundo esses mesmos autores, existem dois tipos básicos de controles: controles externos baseados em medidas e controles internos baseados em valores. A primeira abordagem, para Das e Teng (2001), enfatiza o estabelecimento e utilização de regras formais, procedimentos e políticas para monitorar e recompensar performances desejadas. Esse conjunto de controles também é chamado de formal. Ouchi e Maguire (1975) subdividem os controles formais em duas tipologias principais: controles comportamentais e controles dos resultados destes comportamentos. O controle dos comportamentos serve para garantir que um processo seja apropriado. Nesse caso, a mensuração se dá sobre os comportamentos em si e não sobre os outputs finais normalmente devido ao fato de que, nesses casos, a mensuração dos outputs ou não é possível ou é demasiada imprecisa. Já a mensuração de seus resultados (ou controle de outputs) serve 

para avaliar de modo seguro e acurado o desempenho dos membros. A segunda abordagem, por outro lado, baseia-se no estabelecimento de normas, valores, cultura e na internalização de objetivos para encorajar comportamentos e resultados desejáveis. Esse tipo de controle é também chamado de controle normativo, social ou informal (OUCHI; MAGUIRE, 1975).

Os controles formais tendem a serem mais previsíveis, regulares e envolvem a transferência de informações explícitas, sendo codificadas em regras e procedimentos (BIJLSMA-FRANKEMA; COSTA, 2005). Já os controles sociais são mais incertos, ambíguos e imbricados organizacionalmente e utilizam valores, normas e culturas para encorajarem comportamentos desejáveis (DAS; TENG, 1998) e têm como objetivo reduzir a incongruência de objetivos entre os membros da organização ou entre os parceiros de um relacionamento interorganizacional. A diferença-chave entre os controles sociais e formais reside no fato de que, nos controles sociais, nem os comportamentos nem os resultados destes são especificados no início de sua instauração - ex ante, sendo que seu processo de definição de objetivos é descentralizado e evolui com maior naturalidade, o que explica por que os controles sociais são particularmente apropriados para utilização em circunstâncias ambíguas (DAS; TENG; 2001).

\subsection{Controles, confiança e risco: entrelaçando os conceitos}

Para Inkpen e Currall (2004), a seleção dos controles de mecanismo traz implicações para a avaliação de um parceiro no que tange à confiabilidade do outro parceiro. Sitkin e Roth (1993) argumentam que a implantação de mecanismos formais de controles diminui a confiança do parceiro, porque tais controles fornecem explicações alternativas, seja para a confiança pura ou para a confiança baseada em competência. Assim, a formalização não irá necessariamente minar o desenvolvimento da confiança, mas reduzirá sua velocidade, pois as ações confiáveis serão "descontadas" - a partir da percepção do parceiro que as recebe (INKPEN; CURRALL, 2004). Das e Teng (2001) ainda sugerem que controles formais (de outputs) tendem a focalizar os esforços dos parceiros no curto prazo, o que dificulta a busca de objetivos de longo prazo, que por vezes devem sacrificar ganhos possíveis de serem auferidos mais imediatamente. Como agravante, controles formais podem ser percebidos como um sinal de que os parceiros não são suficientemente competentes para executar os processos a seu próprio modo, de forma que a confiança baseada em competência também é prejudicada. 
Há, no entanto, a possibilidade de os controles, mesmo sendo formais, ensejarem maior nível de confiança entre os parceiros quando do início de seu relacionamento. Isto ocorre se: (a) ambos estiverem imbricados em um mesmo ambiente institucional forte e; (b) ambos estiverem sujeitos aos mesmos controles institucionais externos à relação (BACHMANN; 1999). Segundo o mesmo autor, quando isto ocorre, os parceiros creditam uma confiança inicial maior na relação por terem a convicção de que se seus parceiros incorrerem em comportamentos desviantes, eles serão punidos por um sistema legal eficiente.

Inkpen e Currall (2004) consideram o poder de barganha como outro elemento crítico da relação confiança-controle. A utilização do poder de barganha, ao contrário de reduzir o risco de comportamentos oportunistas, pode gerar resultados inversos, pois o controle assimétrico exercido por um parceiro restringirá a autoridade de tomada de decisão do outro parceiro e também restringirá sua habilidade em atingir seus objetivos com a aliança, podendo essa firma, portanto, procurar compensar sua falta de controle e influência incorrendo em comportamentos oportunistas em áreas sobre as quais seu parceiro não exerce controle (DAS; TENG, 2001; INKPEN; CURRALL, 2004). O resultado mais provável desta soma de elementos é a diminuição não apenas da confiança pura, mas também da confiança baseada em competência, visto que desconfiança alimenta desconfiança, como em uma espiral negativa (INKPEN; CURRALL, 2004).

Os controles sociais, ao contrário dos controles formais, não definem comportamentos e metas a priori, permitindo, assim, a existência de um espaço de interação entre os parceiros e ensejando maior liberdade de ação, o que enseja o aumento da confiança pura e da confiança baseada em competência (DAS; TENG, 2001).

No momento inicial de uma relação, Inkpen e Currall (2004) sugerem que a seleção dos controles é influenciada pela confiança pré-existente entre os parceiros. Segundo a linha de pensamento de Inkpen e Currall (2004, p. 290), “quanto maior o nível inicial de confiança entre os parceiros [...], menor o nível do custo inicial de monitoramento e controle da parceria e maior a propensão e confiança na utilização dos controles sociais". Das e Teng (2001) entendem a situação da mesma forma, adicionando ainda que os controles sociais e formais funcionam melhor onde há altos níveis de confiança, devido a esta diminuir os níveis de resistência no uso dos controles - por parte de quem é submetido a eles, o que subentende que, sem um determinado nível de confiança inicial, será difícil os parceiros estabelecerem entre si padrões comportamentais e valores comuns (DAS; TENG, 2001). Assim, eles propõem que "a confiança pura e a confiança baseada em competência aumentarão a 
efetividade de todos os tipos de controles (comportamental, social e de output) em uma parceria" (DAS; TENG; 2001, p. 265).

Há ainda a questão do risco percebido. Naturalmente, as percepções de risco não são sempre iguais entre os atores sociais, visto que há uma série enorme de modelos mentais e estilos cognitivos diversos, os quais geram diferentes "visões de mundo" (HAYES; ALLINSON, 1998). Nessa linha de raciocínio, Das e Teng (2001) ainda propõem - para a manutenção da parceria - que: a) quanto menor a aceitação ao risco relacional percebido, maiores deverão ser os níveis de confiança pura e de controles comportamentais e sociais; e b) quanto menor a aceitação ao risco de performance percebido, maior a necessidade de confiança baseada em competência e de controles sociais e de outputs.

As correlações existentes entre confiança e controle - citadas neste tópico - tendem a gerar diferentes níveis de riscos percebidos, sejam eles relacionais ou de performance. Das e Teng (2001) resumem essas correlações na Figura 1.

\begin{tabular}{|c|c|c|c|}
\hline & \multicolumn{2}{|c|}{ Controles formais } & Controles informais \\
\hline & Controle comportamental & Controle de Outputs & Controle social \\
\hline $\begin{array}{c}\text { Confiança } \\
\text { pura }\end{array}$ & $\begin{array}{c}\text { Baixo } \\
\text { Risco relacional } \\
\text { Alto } \\
\text { Risco de performance }\end{array}$ & $\begin{array}{c}\text { Moderado } \\
\text { Risco relacional } \\
\text { Moderado } \\
\text { Risco de performance }\end{array}$ & $\begin{array}{c}\text { Baixo } \\
\text { Risco relacional } \\
\text { Moderado } \\
\text { Risco de performance }\end{array}$ \\
\hline $\begin{array}{l}\text { Confiança } \\
\text { baseada em } \\
\text { competência }\end{array}$ & $\begin{array}{c}\text { Moderado } \\
\text { Risco relacional } \\
\text { Moderado } \\
\text { Risco de performance }\end{array}$ & $\begin{array}{c}\text { Alto } \\
\text { Risco relacional } \\
\text { Baixo } \\
\text { Risco de performance }\end{array}$ & $\begin{array}{c}\text { Moderado } \\
\text { Risco relacional } \\
\text { Baixo } \\
\text { Risco de performance }\end{array}$ \\
\hline
\end{tabular}

Fonte: Adaptado de DAS e TENG, 2001, p. 267.

Essa matriz explica como determinado tipo de confiança, agindo em conjunto com determinado tipo de controle, afeta o risco percebido. O exemplo a seguir, ilustrado com base em Das e Teng (2001), possibilita ampliar o entendimento sobre as correlações entre confiança, controle e risco: quando uma firma A tem confiança pura em uma firma B e, concomitantemente, existem controles comportamentais agindo sobre essa firma B, o risco percebido relacional da firma A tende a ser baixo, pois haverá duas forças agindo simultaneamente sobre tal risco (confiança pura e controles comportamentais). Ao mesmo tempo, o risco percebido de performance permanecerá alto, visto que, conforme sugerido no arcabouço teórico, confiança pura e controles comportamentais não agem sobre a performance do parceiro B. Dessa forma, os riscos percebidos (relacionais e de performance) são reduzidos a níveis baixos apenas quando há sobreposição de duas forças sobre eles. 


\section{ASPECTOS METODOLÓGICOS}

A presente pesquisa se caracteriza por ser de caráter qualitativo, o qual, segundo Malhotra (2001), proporciona insights valiosos, que permitem alcançar uma compreensão qualitativa das razões e motivações subjacentes ao problema proposto. A estratégia de pesquisa pode ser classificada como exploratória, pois, como o estudo da temática abordada neste estudo é uma questão emergente no meio acadêmico, entende-se que este estudo possibilita ampliar a compreensão e a familiaridade desse complexo fenômeno. O método adotado para realização desta pesquisa é o do estudo de casos múltiplos (YIN, 2004).

Dessa forma, o presente trabalho pretende explorar como os tipos de confiança e controles se afetam mutuamente e como essa inter-relação entre ambos afeta os níveis de riscos relacionais e de performance percebidos em um ambiente de cadeia de suprimentos. Para isso, a pesquisa foi realizada em uma díade de uma cadeia de suprimentos, conforme se pode visualizar na Figura 2:

Figura 2 - Desenho de pesquisa

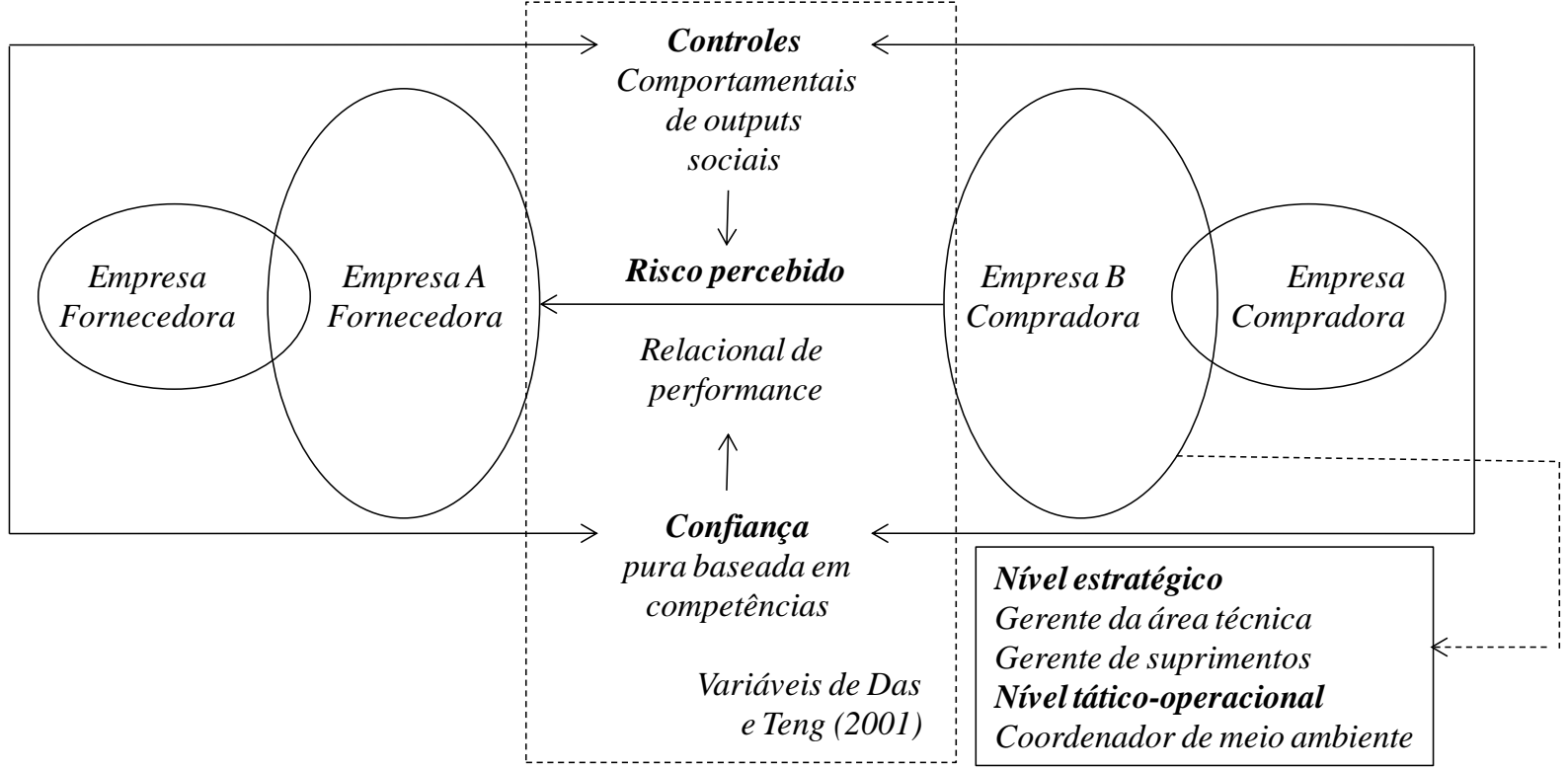

Fonte: Elaborado pelos autores deste artigo.

A Figura 2 resume a proposta de pesquisa, a qual se baseia nos pressupostos de Das e Teng (2001). Esses pressupostos estão explícitos no modelo e são os seguintes: a empresa B percebe determinado nível e tipo de risco (relacional e de performance) em relação à empresa A; a percepção desses tipos de risco sofre influência de dois tipos de confiança (pura e baseada em competência) e de três tipos de controles (comportamentais, de outputs e sociais), 
os quais, por sua vez, exercem influência uns sobre os outros (a confiança sobre os controles e vice-versa), concomitantemente.

A cadeia de suprimentos escolhida foi selecionada por ser uma das maiores do Brasil, seja em termos de empregos diretos e indiretos ou em termos de faturamento bruto total. Ela é composta por um grupo central, formado por uma empresa principal (matriz), presente no Brasil desde a década de 1950, por dezessete grupos empresariais franqueados e independentes, fabricantes de bebidas não alcoólicas, além de outros grupos que, em conjunto, somam mais de quarenta complexos fabris. Além dessas fábricas, essa cadeia de suprimentos ainda é formada por uma grande quantidade de fornecedores diretos, indiretos e por um grande conjunto de parceiros-clientes. Apenas esse grupo central gera em torno de trinta e um mil empregos diretos e em torno de trezentos e dez mil empregos indiretos e faturou, em 2007, um valor total maior do que doze bilhões de reais.

Observando-se dentro dessa cadeia de suprimentos, a empresa chamada compradora (denominada B) representa algo em torno de 3\% do volume total de negócio de toda a cadeia de suprimentos, sendo responsável por produzir e abastecer parte da região sul do Brasil com bebidas não alcoólicas, que levam a marca da matriz. Essa empresa concentra o maior volume setorial de negócios em sua área de atuação na mencionada cadeia de suprimentos, sendo este o fato principal de sua escolha.

A empresa fornecedora (denominada A) foi escolhida devido a: (a) fornecer um dos serviços de maior impacto potencial na imagem, na viabilidade do negócio da empresa $\mathrm{B}$ e nos shareholders da empresa compradora (gestão de resíduos industriais) - ou seja, a empresa A foi escolhida por prestar um serviço que apresenta grandes riscos à $\mathrm{B}$; (b) ter começado a prestar serviços à empresa B há relativamente pouco tempo, em torno de três anos, o que permite melhor compreender, desde o início do estabelecimento da relação entre ambas as empresas, a dinâmica das variáveis analisadas. A empresa A fornece serviços referentes à gestão de resíduos, desde sua coleta até seu processamento ou disposição adequada. Essa empresa faturou em 2007 aproximadamente 120 milhões de reais e atualmente possui 327 funcionários.

O motivo de ter sido selecionada apenas uma díade para a realização desta pesquisa baseia-se no fato de que apenas uma empresa presta serviços ambientais a B. Adicionar outras organizações à amostra significaria agregar à pesquisa empresas que teriam uma natureza relacional diferente com B e com características de performance e de resultados igualmente diferentes, o que aumentaria a probabilidade de distorção dos resultados. 
PUC Minas E\&G - REVISTA ECONOMIA E GESTÃO

ISSN 1984-6606

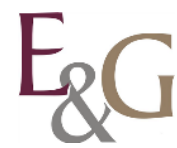

Quanto aos sujeitos de pesquisa, foram selecionadas pessoas da empresa B: a) responsável pela definição das respectivas políticas de compras desta (gerente de suprimentos); b) cliente interna, atuando na empresa B e, portanto, receptora direta dos serviços prestados pela empresa $\mathrm{A}$, e responsável pela operacionalização das políticas ambientais da empresa B (coordenadora de meio-ambiente); e c) responsável pela definição das políticas de meio-ambiente da empresa B (gerente técnica). A seleção dos sujeitos ocorreu com uma amostra não probabilística intencional, devido ao impacto de suas ações nos controles e confiança interorganizacionais, a nível estratégico, tático e operacional; e a serem os únicos pontos-chave de contato da empresa B com a empresa A e assim constituírem o grupo de análise necessário para a consecução dos objetivos deste trabalho.

Os dados foram coletados em entrevistas semiestruturadas - as quais foram gravadas e posteriormente transcritas para a realização da análise, sendo examinadas pela técnica da análise de conteúdo (BARDIN, 1977), que objetiva fazer a conexão entre a teoria prévia levantada na revisão de literatura e o que foi encontrado na coleta de dados; e em análise documental, que objetivou a busca de informações adicionais às entrevistas e assim o aprofundamento da análise da relação estabelecida entre as organizações. As informações foram analisadas conforme as variáveis de Das e Teng (2001) descritas na Figura 2.

O presente artigo apresenta as limitações de pesquisa inerentes ao estudo de caso. Seguindo Yin (2004), uma das limitações desse método é o fato de o estudo de caso fornecer pequena base para generalizações científicas. Outra questão a ser considerada são as respostas obtidas nas entrevistas. Em nenhum momento esgota-se a possibilidade de que somente estas sejam as respostas para a problemática desta pesquisa. 


\section{APRESENTAÇÃO E DISCUSSÃO DOS RESULTADOS}

Para alcançar o objetivo proposto neste trabalho, em um primeiro momento analisaram-se os termos confiança, controles e riscos na perspectiva dos entrevistados. Logo após, esses conceitos foram entrelaçando, utilizando-se o modelo proposto por Das e Teng (2001).

\subsection{A Evolução da confiança, dos controles e do risco na perspectiva dos entrevistados}

Com base nas premissas apresentadas na teoria e metodologia, os resultados serão apresentados em duas fases. A primeira fase mostrará a fase inicial da relação entre ambas as empresas e como a confiança, os controles e os riscos foram tratados nesta etapa, e a segunda fase apontará o desenvolvimento da relação e como esses três constructos influenciaram-se mutuamente, até o tempo presente.

Quanto ao horizonte de relacionamento, a empresa $\mathrm{A}$ presta serviço à empresa $\mathrm{B}$ há três anos, e o motivo da seleção desta por B deve-se a sua alta capacidade técnica, seu custo atrativo, sua proximidade física em relação à $\mathrm{B}$ e, principalmente, à grande necessidade desta em melhorar a qualidade, conformidade e eficácia de sua gestão de resíduos. Destacou-se então, no momento da escolha da empresa, a confiança baseada em competência e, ao mesmo tempo, ea redução do risco de performance: a firma B fundamentou sua tomada de decisão mais em fatores técnico-negociais e na capacidade percebida da empresa A em cumprir com suas obrigações profissionais, do que na percepção de boa-fé desta. É o que revelam as falas dos executivos entrevistados:

A gestão de resíduos aqui era algo realmente ruim. Ninguém sabia direito para onde eles iam [...]. Desse jeito, não seríamos certificados na ISO 14000 nunca. [...] Além disso, eles são perfeitos tecnicamente (Fala da coordenadora de meio ambiente).

A empresa A veio com uma proposta de preço muito boa [...] Eles quantificaram e qualificaram os resíduos, que eram coisas complexas e caras. [...] Eles deram soluções técnicas para reciclagem de uma série de sobras de processo que antes a gente não enviava para reciclagem [...] Agora sabemos para onde vai cada um dos nossos resíduos industriais (Fala da gerente técnica).

Eles eram a fornecedora mais próxima de nós. Se fôssemos contratar outra empresa, custaria uma fortuna. E mesmo que este contrato nos custe caro, acaba saindo barato porque a gente diminui o risco de 
receber multas e sofrer danos a nossa imagem por problemas com resíduos [...]. (Fala do gerente de suprimentos).

Embora os executivos da empresa B tenham enfatizado a redução de risco de performance no início de sua relação com A - provavelmente devido a sua carência técnica e consequente necessidade de organização de seus resíduos, conforme as falas explicitaram - o risco relacional também recebeu atenção, embora em menor grau:

[...] procuramos verificar com outras empresas se eles eram honestos e comprometidos... Se eles cumpriam com o que diziam. [...] As respostas foram positivas [...] Também verificamos a situação de conformidade legal deles junto aos órgãos responsáveis e estava tudo ok.. (Fala da gerente técnica).

Constata-se também que o motivo de se tentar entender qual o nível de risco (de performance e relacionamento) que a empresa $\mathrm{A}$ oferecia à $\mathrm{B}$ tinha como causa principal os grandes prejuízos imputados à $\mathrm{B}$ caso $\mathrm{A}$ incorresse em erro técnico ou oportunismo. A gerente técnica mostra claramente o impacto negativo potencial que A tem sobre a organização B:

[...] os riscos são enormes. A gente poderia ter que fechar a fábrica! [...] a gente sempre é co-responsável aos terceirizados e quarteirizados. [...] Se a empresa A resolvesse 'aprontar', a gente teria que pagar multas enormes, além de ter a imagem muito comprometida com os consumidores. (Fala da gerente técnica).

Mesmo assim não se constatou que riscos tão altos como estes geraram acréscimo ou recrudescimento nos controles iniciais. Essa constatação é corroborada por Das e Teng (2001), quando estes sustentam que um alto nível inicial de confiança - que foi verificado nas falas das duas gestoras - diminui a percepção de riscos. A seguinte fala da coordenadora de meio ambiente corrobora essa posição: "O nível de confiança inicial era elevado, visto que a empresa A foi recomendada por outras empresas e apresentou alta capacidade técnica. [...] No início, os controles que tínhamos eram aqueles exigidos pelas políticas ambientais da nossa matriz" (Fala da coordenadora de meio ambiente).

Realizando-se uma análise da primeira minuta contratual definida entre as empresas A e B (no início de relacionamento entre ambas), verifica-se que o nível de detalhamento e a amplitude dos controles iniciais de B para A eram relativamente baixos. Praticamente todas as cláusulas contratuais orbitavam em torno de questões gerais, como cumprimento da legislação trabalhista, de segurança do trabalho e de meio ambiente; licenças e autorizações de operação vigendo; cuidados básicos de transporte e legalização deste; e confidencialidade contratual. O 
único ponto do instrumento que destoa destes resume-se a uma cláusula que institui $10 \%$ de multa para a empresa A sobre o valor contratual, caso esta descumpra com suas obrigações estipuladas no contrato. Mesmo assim, há de considerar-se que, frente aos riscos citados pela gerente técnica, essa multa representa um valor relativo bastante baixo.

Além disto, nota-se também o ambiente institucional agindo como um redutor de incertezas e riscos, em conjunto com controles sociais. A coordenadora de meio ambiente e a gerente técnica entendem que, caso a empresa A cometa erros graves para com a organização $\mathrm{B}$, seja em termos éticos ou de performance, aquela será punida pelo mercado, visto que sua imagem será prejudicada. Ou seja, a percepção de ambas as executivas a respeito da eficácia dos controles social exercidos sobre A acaba por diminuir a sensação de insegurança e, consequentemente, a percepção de risco relacional e de competência:

A sensibilização das pessoas tem aumentado em relação à questão ambiental [...] a sociedade pode punir a empresa, porque ela vai estar agredindo todo mundo e não só a minha empresa [...] ela vai estar comprometendo as gerações futuras também. [...] Se ela não cumprir com o que a nossa matriz pede, ela vai se 'queimar' com todos os outros fabricantes do país. (Fala da gerente técnica).

Caso ela gerar perdas para nós, que nos comprometam junto ao mercado, ela sofrerá as consequências junto, por que ela é uma empresa grande também, igual a nossa. [...] Na justiça não teria aquela história de empresa grande que explora a empresa pequena [...] A briga seria de igual para igual. [...] Eles teriam sérios problemas de conseguir outros clientes... O que diríamos para quem nos ligasse pedindo informações deles? (Fala da Coordenadora de meioambiente).

Considerações como estas - existência de confiança e baixa utilização de controles formais - fazem supor que, inicialmente, os executivos da empresa B entenderam a confiança e o controle a partir de uma perspectiva substitutiva. Assim, a constatação por B de que a empresa A era confiável em termos de competência e de relacionamento, aliada à percepção de segurança institucional, levou a uma redução dos riscos percebidos (de performance e relacionamento), o que, por sua vez, acarretou menor necessidade de controles formais.

Assim, a fase inicial do relacionamento entre as organizações A e B foi marcada pelo que Inkpen e Currall (2004) chamam de "lua-de-mel relacional", caracterizada por um alto nível de confiança e pela inexistência ou baixo índice de conflitos disfuncionais. Ainda segundo esses autores, ao longo do tempo, na medida em que as empresas parceiras e os gerentes parceiros aprendem uns sobre os outros e a relação entre ambas as empresas torna-se 

uma entidade operacional, o nível de confiança interorganizacional muda, o que significa que a confiança e os controles devem ser vistos como conceitos que evoluem, não são estáticos. Assim sendo, as entrevistas revelam que, com o passar do tempo, a relação entre as empresas A e B ganhou aspectos e características diferentes daquelas observadas nos primeiros meses de relacionamento. Um fato em específico abalou seriamente a confiança do gerente de suprimentos em relação à empresa A: após cerca de 1 ano e 6 meses de vigência do contrato entre ambas as firmas, o órgão governamental, responsável pelo recebimento e processamento dos resíduos líquidos entregues pela empresa A (gerados pela empresa B), emitiu fatura superior a R\$ 300 mil reais contra a organização B pelo fato de ela não estar efetuando os pagamentos referentes às taxas de recebimento e processamentos de seus resíduos. Diante disso, B entendeu que tais montantes eram de responsabilidade de A. No entanto A interpretou que a ela cabiam todos os custos operacionais das operações ambientais objetos do contrato, mas não gastos adicionais advindos de terceiros.

A partir desse momento, as percepções do gerente de suprimentos passam a divergir sensivelmente daquelas mantidas pela coordenadora de meio ambiente e pela gerente técnica. Para o gerente de suprimentos, uma relação que começou "transparente e equilibrada", após a ocorrência de uma série de problemas indesejáveis, tende a enfraquecer.

Quando perguntado ao gerente de suprimentos se ele confia na integridade e honestidade da empresa A passado este tempo, este respondeu que não, pois "ela várias vezes não cumpriu o que falou [...] algumas vezes ela fugiu das suas obrigações contratuais [...], sempre é preciso 'ficar em cima' dela para ela fazer o que a gente acordou com os próprios diretores dela". Essa visão do gerente de suprimentos desencadeou a instauração de controles adicionais: "Ficou claro que não podemos confiar neles [...]. A gente mudou o contrato. Foi inclusa uma série de obrigações que tinham sido combinadas entre a gente e que eles não cumpriram [...]". A essas indisposições do gerente de suprimentos somaram-se outras, as quais vieram a agravar a relação entre ele e a empresa A: “(...) uma vez, ficamos sabendo que havia produtos nossos" - que, contratualmente, deveriam ser descartados como produtos nãoconforme por A - "sendo vendidos por eles. Imagina só isto! E se alguém passa mal, como fica essa pessoa?! E nós, como ficamos?!”.

Devido a tais questões, esse gerente revelou, em sua entrevista, uma desconfiança aberta em relação à organização A quanto a suas intenções. Quando perguntado sobre como ele entendia o compartilhamento de valores e princípios entre ambas as organizações, sua resposta foi direta: "Isso não existe. Pois minha empresa tem princípios como transparência e 
integridade, os quais a empresa A transparece não possuir [...], ela passa a ideia de ser uma empresa oportunista $[\ldots]$ ".

Mesmo com a ocorrência desse evento (indecisão quanto ao pagamento dos resíduos), as gestoras de meio ambiente e área técnica mencionaram ainda confiar na outra parte devido a sua transparência e honestidade na tratativa dos problemas ocorridos na relação. A coordenadora de meio ambiente, por exemplo, afirmou que "A verdade é que às vezes eles cumprem mais o contrato que a gente [...]. Às vezes a gente controla menos empresas que são bem mais prejudiciais [...]”. A gerente da área técnica, por sua vez, disse que:

Houve problemas. Mas sempre que isto aconteceu, eu ligava para eles e eles resolviam se não na hora, em bem pouco tempo. [...] Quando não há solução para um problema, eles te dizem na hora [...] Às vezes eles são ríspidos... Mas é melhorar ouvir uma verdade difícil que ficar na mentira. (Fala da gerente técnica).

Quando foi perguntado à coordenadora de meio ambiente se já houve algum fato crítico que tenha abalado a relação de confiança existente entre ambas as empresas, ela também trouxe à tona a questão do pagamento dos resíduos líquidos. Mas, ao contrário do gerente de suprimentos, ela percebeu o ocorrido de forma diversa, como sendo "natural em uma relação que envolve dinheiro". Em outro momento, a gestora comenta que "fizeram muito alarde com esta questão [...] Afinal, não deu problema com isto... Eles assumiram a bronca sozinhos, pagaram tudo". Mais adiante, a gestora diz que:

[...] eles são transparentes [...] Quando saiu uma história que eles estavam vendendo nossos produtos, os dois diretores deles vieram até aqui e verificaram que realmente o funcionário deles alocado aqui na fábrica estava desviando produtos. [...] Eles despediram o colaborador deles na hora. Isto é uma demonstração de que eles não compactuam com comportamentos indevidos. (Fala da coordenadora de meio ambiente).

Entretanto, mesmo com as responsáveis pelo meio ambiente e pela área técnica percebendo a situação de modo diverso do gerente de suprimentos, foi redigido um novo contrato em substituição ao anterior. $\mathrm{O}$ detalhamento desse novo instrumento, assinado pelas duas partes, transparece as sensíveis mudanças ocorridas no relacionamento entre ambas as empresas: questões que, no contrato antigo, eram tratadas com afirmativas generalizadas, no novo contrato, passaram a ser detalhadas em profundidade. Garantias e salvaguardas foram adicionadas ao instrumento, sendo as penalidades cabíveis em caso de dano à $\mathrm{B}$ substancialmente maiores que aquela anteriormente definida. $\mathrm{O}$ prazo contratual foi 

diminuído e passaram a ser exigidos vários documentos também dos quarteirizados. Foi estipulado um calendário para a realização de auditorias nas dependências da empresa $\mathrm{A}$ e várias atividades realizadas por A nas dependências de B começaram a ser acompanhadas e avaliadas por meio de check-lists, além do que foram solicitadas reuniões periódicas de acompanhamento das atividades junto aos diretores da empresa A. Em suma, um instrumento legal de nove páginas passou a ter 43 páginas. Além da formalização de tais controles e obrigações, foram instaurados ainda controles adicionais na área de reciclagem da empresa B, onde está alocada a unidade operativa da organização A. Esses controles - como, por exemplo, uma segunda pesagem dos resíduos vendáveis - foram definidos pelo gerente de suprimentos com o objetivo, segundo ele, de "não sermos roubados [...] Têm resíduos que nós vendemos para eles - plástico, papelão, madeiras, como está definido no contrato [...]. Quem diz que eles não estão levando mais resíduos que os controles deles afirmam?”. Assim, quando questionado a respeito dos principais motivadores de sua desconfiança, o gerente de suprimentos diz que "Eu vejo como principal motivo a atuação dos diretores da empresa A: eles não agem sempre com boa-fé... Qualquer oportunidade que eles têm de ganhar, eles fazem... Mesmo que a gente perca".

Essas situações, constatadas na fase intermediária e atual do relacionamento entre as organizações A e B, apontam que a coordenadora de meio ambiente e a gerente técnica viram como positivo e de baixo risco (tanto relacional quanto de performance) o relacionamento com a empresa A, mas foi a percepção do gerente de suprimentos que prevaleceu. Entretanto, embora a teoria, normalmente, afirme que os controles formais e o uso do poder de barganha tendam a aumentar os comportamentos oportunistas da parte que os sofre (DAS e TENG, 2001; INKPEN; CURRALL, 2004), não foi o que se constatou nas entrevistas. Como a interface operacional da empresa $\mathrm{A}$ ocorre junto à área técnica e ambiental da empresa $\mathrm{B}$, foram estas últimas que acabaram sentindo os efeitos dos novos controles. Segundo as duas gestoras, embora a empresa A tenha reclamado a elas a respeito dos novos controles e obrigações, "em nenhum momento ela deixou de cumprir com o novo contrato, sendo que ele nem assinado ainda foi", conforme colocou a gerente técnica. Mas, ao contrário, conforme falou a responsável pelo meio ambiente:

[...] como eles sentiram que aumentamos os controles por causa das histórias do produto não-conforme e do pagamento dos resíduos, eles passaram a se esforçar mais para mostrar que realmente são sério [] $\mathrm{O}$ contrato novo nem foi assinado ainda e eles já estão cumprindo as novas exigências, sendo que já teríamos que estar pagando o novo 
A explicação para a contínua desconfiança por parte do gerente de suprimentos em relação à empresa A, mesmo após esta acatar os novos controles e obrigações, encontra respaldo na abordagem de Inkpen e Currall (2004, p. 590): "Se a firma 1 interpreta as ações confiáveis da firma 2 como sendo em muito uma função dos controles formais em oposição à livre escolha de agir confiavelmente, então a firma 1 descontará a aparente confiabilidade da firma 2". Essa divergência perceptiva também pode ser explicada por Bijlsma-Frankema e Costa (2005), os quais entendem a estrutura formal da organização como sendo um importante fator contextual que pode influenciar a maneira como os indivíduos gerenciam suas dependências críticas, imbricando-as em relações de confiança.

\subsection{Entrelaçando os conceitos com base nos resultados}

Os resultados mostraram a dinâmica relacional evolutiva das empresas A e B. Na fase inicial, constatou-se que ambas as empresas interagiam mais com base nos dois tipos de confiança e nos controles sociais do que com base nos controles formais. Observou-se que, em tal momento, houve incremento de confiança por parte das gestoras técnica e de meio ambiente em relação à outra empresa, passando elas a perceberem os riscos de performance e relacionamento como baixos. Já o gerente de suprimentos não desenvolveu a confiança pura, mesmo conservando a confiança, baseada em competência, em A. Posteriormente, a partir da ocorrência de um evento específico, o gerente de suprimentos mudou sua percepção em relação às boas intenções de $\mathrm{A}$ - o que afetou seriamente sua confiança pura. Conforme o modelo de Das e Teng (2001) prevê, a resultante dessa dinâmica do gerente de suprimentos foi o aumento do risco relacional percebido, que acabou gerando um forte aumento dos controles formais.

Dessa forma, a relação entre ambas as empresas passou a ter dois vetores principais. De um lado, posicionaram-se as gestoras técnica e de meio ambiente, que percebem a relação como sendo de baixo risco e de outro o gerente de suprimentos, o qual a vê como sendo altamente arriscada, em termos relacionais. Assim, a premissa teórica de que, na medida em que a confiança entre os parceiros aumenta, haverá maior fé em estruturas alternativas de governança, enfatizando contratos relacionais e informais (INKPEN; CURRALL, 2004), coube apenas às duas gestoras, as quais viram como desnecessário o aumento dos controles e continuaram sempre a relacionar-se com a empresa A de modo informal e direto. Ao gerente 
de suprimentos, coube a premissa de Powell (1996, apud MÖLLERING; 2005): a falta de características de similaridade (shared world view) e de confiança "natural" entre as empresas leva a relacionamentos mais formais, que são mais custosos e demorados. Ainda há de considerar-se que o novo contrato e controles foram possíveis devido às diferenças dos papéis hierárquicos e de poder exercidos pelo gerente de suprimentos e pelas duas gestoras.

Os novos mecanismos de segurança supracitados acabaram por trazer custos de transação adicionais à relação. Mas, ao contrário do que afirmam alguns autores (INKPEN; CURRALL, 2004; DAS; TENG, 2001), a nova estrutura de governança não prejudicou profundamente a cooperação entre as empresas. As novas tratativas dadas catalisaram ações positivas por parte da empresa $\mathrm{A}$, que, ao contrário do que se poderia esperar, não reagiu negativamente. A explicação pode estar na confiança interpessoal e na diferença de papéis. Como as gestoras têm uma atuação mais próxima da empresa $\mathrm{A}$, seu conhecimento a respeito dos detalhes da operação desta tende a ser maior. O gerente de suprimentos, por seu turno, tem acesso apenas às informações gerais do processo e de seus resultados, além de ter maior foco em resultados financeiros. Conforme Spekman, Kamauff e Myhr (1998) expõem, normalmente os compradores são treinados com forte ênfase na redução de custos, por vezes deixando de lado aspectos vitais como a construção de parcerias.

A soma desses resultados, aplicada à matriz de Das e Teng (2001), explica-se em momentos distintos. A Figura 3 mostra a relação confiança-controles-riscos na fase (a) inicial e (b) intermediária - que se iniciou após o conflito estabelecido devido à indefinição do pagamento da taxa governamental de recolhimento e processamento de resíduos - e atual do relacionamento entre as empresas A e B. Conforme já exposto, na fase inicial, tanto a confiança pura quanto a confiança baseada em competência eram consideradas altas para os três gestores de B. Concomitantemente, os controles formais nessa fase eram poucos, sendo os controles sociais e institucionais os mais utilizados. A soma desses elementos levou a uma percepção de ambos os tipos de riscos como sendo baixa, corroborando o estabelecido pela teoria. 
Figura 3 - Entrelaçamentos dos construtos com base em Das e Teng (2001)

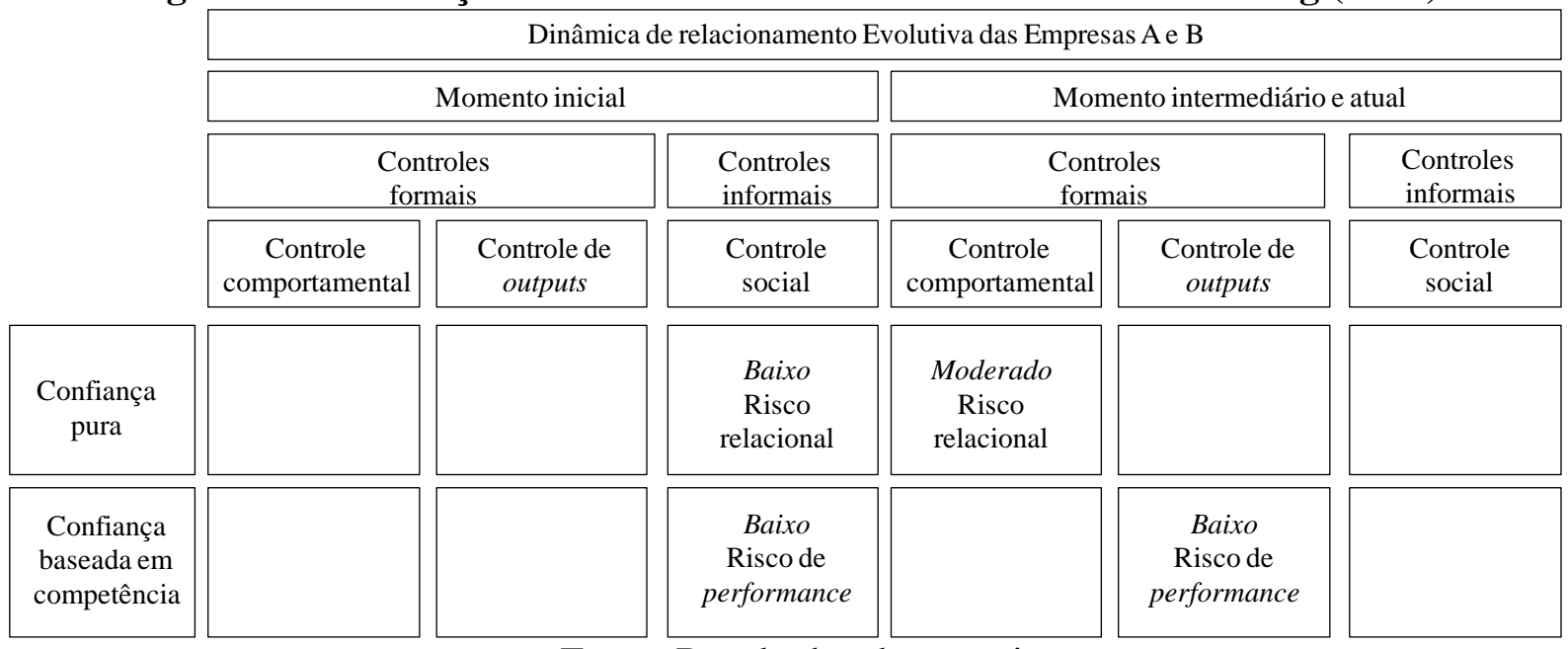

Fonte: Resultados da pesquisa

$\mathrm{Na}$ fase mais avançada da relação entre A e B, as gestoras técnica e de meio ambiente continuaram com o mesmo padrão de confiança e controle. O gerente de suprimentos, diferentemente, mudou de modo profundo sua percepção em relação a essas variáveis durante a evolução do relacionamento com a organização A. Conforme apontado nos resultados, sua confiança pura na empresa A praticamente extinguiu-se nessa fase, embora sua confiança, baseada em competência, naquela empresa tenha se mantido a mesma. Como resposta ao aumento do risco relacional, foram instaurados novos controles de output e de comportamento, que acabaram então a posicionar o risco relacional em um patamar moderado (produto da soma de duas forças: controles formais e confiança baseada em competência), enquanto o risco de performance continuou sendo considerado baixo (devido à sobreposição da confiança baseada em competência e dos controles de output). 


\section{CONSIDERAÇÕES FINAIS}

Controles, riscos e confiança são conceitos de forte presença tanto nas organizações como na vida privada dos indivíduos. Entender como tais construtos funcionam e interagem com os diversos contextos sociais, nas mais diversas situações, e mesmo entre si mesmos, significa avançar no desenvolvimento de relações mais eficazes e produtivas. E entende-se que este trabalho contribui nesse sentido, seja em termos teóricos ou empíricos.

A contribuição acadêmica deste trabalho reside no fato de não se observarem, nos principais periódicos científicos do Brasil, trabalhos que compreendam a imbricação teórica entre confiança, controle e risco, sendo esses construtos trabalhados de modo separado. Assim, este artigo traz consigo novas linhas de pesquisa que estão sendo adotadas sobre a temática fora de nosso país, nos grandes centros de estudos sociais.

Este artigo contribui empiricamente para o melhor entendimento dos gestores principalmente daqueles que trabalham nas fronteiras das organizações (tanto a jusante como a montante) - a respeito da dinâmica das inter-relações estabelecidas entre confiança, riscos e controles. Obter esse entendimento gera aos executivos de diversas posições hierárquicas ferramentas adicionais a serem utilizadas nas tomadas de decisão referentes ao gerenciamento de contratos, controles, políticas de relacionamento com fornecedores e clientes e resolução de crises relacionais com outros parceiros da cadeia de suprimentos.

Cada vez mais se fazem necessários a colaboração interorganizacional, o trânsito rápido de ideias e informações, o compartilhamento de ativos e de aptidões e a aprendizagem interorganizacional. Conforme vários autores mencionam, sem confiança a consecução de tais objetivos é largamente dificultada. Por outro lado, os ativos estratégicos das organizações concentram-se de forma crescente na mente das pessoas e, assim sendo, tornam-se altamente voláteis e de difícil controle. Assim sendo, unir confiança e controle, sob a ótica da diminuição de riscos não é uma tarefa fácil, mas é seguramente uma tarefa necessária. Melhor entender como ambas funcionam, certamente aumenta as chances de sucesso daqueles que empreendem essa difícil tarefa.

Quanto às limitações da pesquisa, deve ser considerado que as considerações feitas a respeito das correlações estabelecidas entre controles, confiança e riscos podem ser diferentes em outras díades. Logo, são requeridos estudos adicionais a fim de validar as considerações sustentadas neste trabalho, para então poderem-se posteriormente realizar as generalizações objetivadas nas pesquisas de natureza descritiva. 


\section{REFERÊNCIAS}

BACHMANN, R. Trust, Power and control in trans-organizational relations. Technical University Hamburg. Paper presented to the SASE-conference. Madison/Wiscosin, USA, July, 1999.

BARDIN, L. Análise de Conteúdo. Lisboa: Edições 70, 1977.

BARNEY, J. B.; HANSEN, M. H. Trustworthiness as a source of competitive advantage. Strategic Management Journal, v. 15, Special Issue, p. 175-199 1994.

BIJLSMA-FRANKEMA, K; COSTA, A. C. Undertanding the trust-control nexus. International Sociology, v. 20, n. 3, p. 259-288, 2005.

BRANDENBURGER, A. M.; NALEBUFF, B. J. Co-opetition: A Revolution Mindset That Combines Competition and Cooperation: The Game Theory Strategy That's Changing the Game of Business. New York: Doubleday Business, 1997.

CHU, S. Y.; FANG, W. C. Exploring the Relationships of Trust and commitment in Supply Chain Management. Journal of American Academy of Business, Cambridge, v . 9, n. 1, p. 224-228, 2006.

DAS, T. K.; TENG, B. S. Between trust and control: developing confidence in partner cooperation in alliances. Academy of Management Review, v. 23, n. 3, p. 491-502, 1998.

DAS, T. K.; TENG, B. S. Trust, control, and risk in strategic alliances: an integrated framework. Organization Studies, v. 22, n. 2, p. 251-283, 2001.

DONEY, P. M.; CANNON, J. P. An examination of the nature of trust in buyer-seller relationships. Journal of Marketing, v. 61, n. 2, p. 35-51, 1997.

GRANOVETTER, M. Economic action and social structure: the problem of embeddedness. American Journal of Sociology. v. 91, n. 3, p. 481-510, 1985.

HAYES, J.; ALLINSON, C. W. Cognitive style and the theory and practice of individual and collective learning in organizations. Human Relations, v. 51, n. 7, p.847-871, 1998.

HUAN, S.H.; SUNIL, K. S.; WANG, G. A review and analysis of supply chain operations reference (SCOR) model. Supply Chain Management, v. 9, n.1, p. 23-29, 2004.

INKPEN, A. C.; CURRALL, S. C. The coevolution of trust, control, and learning in Joint Ventures. Organization Science, v. 15, n. 5, p. 586-599, 2004.

KWON, I. W.; SUH, T. Trust, commitment and relationships in supply chain management: a path analysis. Supply Chain Management, v. 10, n. 1, p.63-76, 2004.

LARSON, P. D.; ROGERS, D. S. Supply chain management: definition, growth and approaches. Journal of Marketing Theory and Practice, v. 6, n. 4, p. 412-424, 1998. 
LEE, H.; BILLINGTON, C. Managing supply chain inventories: pitfalls and opportunities. Sloan Management Review, v. 33, n. 3, p. 65-73, 1992.

MALHOTRA, N. K. Pesquisa de Marketing: uma orientação aplicada. Porto Alegre, Bookman, 2001.

MÖLLERING, G. The trust/control duality. International Sociology, v. 20, n. 3, p. 39-50, 2005.

MORGAN, R. M.; HUNT, S. D. The commitment-trust theory of relationship marketing. Journal of Marketing, v. 58, n. 3, p. 20-38, 1994.

NEW, S. J. The scope of supply chain management research. Supply Chain Management, v. 2, n. 1, p. 285-301, 1997.

OUCHI, W. G.; MAGUIRE, M. A. Organizational control: two functions. Administrative Science Quarterly, v. 20, n. 4, p. 559-569, 1975.

SAHAY, B. S. Understanding trust in supply chain management relationships. Industrial Management \& Data Systems, v. 103, n. 8, p. 453-470, 2003.

SCC. SCOR 8.0 Overview Booklet. Supply-Chain Council. Disponível em: <http://supplychain.org/page. ww? section=SCOR+Model\&name=SCOR+Model $>$. Acesso em: 2 de abril de 2008 .

SITKIN, S. B.; ROTH, L. R. Explaining the limited effectiveness of legalistic "remedies" for trust/distrust. Organization Science, v. 4, n. 3, p. 367-392, 1993.

SPEKMAN, R. E.; KAMAUFF, J. W.; MYHR, N. An empirical investigation into supply chain management: a perspective on partnerships. Supply Chain Management, v. 3, n. 2, p. 62-69, 1998.

SVENSSON, G. Perceived trust towards suppliers and customers in supply chains of the Swedish automotive industry. International Journal of Physical Distribution \& Logistics Management, v. 31, n. 9, p. 647-662, 2001.

WILLIAMSON, O. The Economic Institutions of Capitalism. Free Press, New York, NY. 1985.

WU, W. Y.; CHIAG, C. Y.; WU, Y. F; TU, H. F. The influencing factors of commitment and business integration on supply chain management. Industrial Management \& Data Systems, v. 104, n. 3, p. 322-333, 2004.

YIN, R. K. Estudo de Caso: Planejamentos e Métodos. 3. ed. São Paulo: Bookman, 2004. 